\title{
Volunteering at an adventure camp for epidermolysis bullosa
}

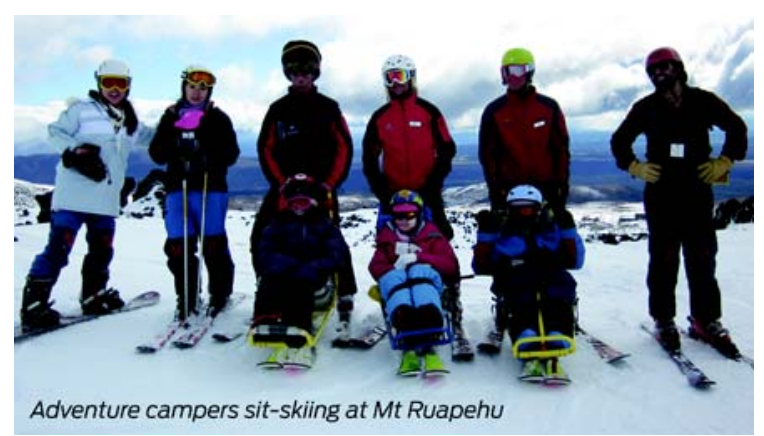

\section{An adventure holiday provides respite, and an awareness of burdens carried by patients and their carers}

(2. pidermolysis bullosa (EB) is a rare hereditary genodermatosis, classified into simplex, junctional and dystrophic EB (DEB), and Kindler syndrome. ${ }^{1}$ Patients with severe types of EB, such as junctional EB and recessive DEB (RDEB), experience a significant daily burden of disease due to extremely fragile skin and limited physical ability.

In 2004, an inaugural adventure camp for Australasian patients with RDEB was held by a non-profit charitable trust, the DEB Research Association New Zealand (DEBRA NZ), followed by two more camps in 2006 and 2007. ${ }^{2}$ The many positive responses to these encouraged DEBRA NZ to organise another adventure camp in 2010.

The 2010 camp aimed to give patients with RDEB fruitful outdoor experiences, to encourage them to socialise with others, and to provide respite care for their regular caregivers.

Fifteen people with EB, including six with RDEB, aged 15-39 years spent 9 days in the North Island of New Zealand. Of the patients with RDEB, four were female, compared with none of five on the 2007 camp. This substantial increase suggests that positive feedback from the previous camp encouraged both sexes to participate safely in physically challenging activities.

There was a high carer-to-patient ratio on the camp, and carers included experienced and inexperienced medical staff and other volunteers. Assisting the patients, there were two specialist nurses, a registered nurse, three medical students, four caregivers, and the director and the projects officer of DEBRA NZ. The DEBRA NZ team was an important part of the group, as they were experienced in dealing with EB trauma in the field.

The camp included 3 days skiing at Mt Ruapehu, a day rafting on the Tongariro River, and the final 2 days sightseeing in Auckland and visiting Butterfly Creek. The time spent between volunteers and the young patients allowed the groups to develop intimate friendships and an understanding of each other's lifestyles.

Skiing and river rafting were the central activities, as these were the favourite challenges from the previous camps. The patients sat on modified sit-skis, which consisted of a plastic platform covered with padded seats attached to two skis. Extra foam padding was placed on the seat and under the seatbelts to minimise friction to their skin. Professional ski instructors used guiding straps attached to the handle of the sit-ski to control steering and speed. The height could be modified so that patients did not need to get out of their sit-skis when they were transferred on and off the chairlift. They skied down with the help of two other skiers placed to avoid any collisions.

For river rafting, two rafts were used. On each raft, three patients sat on legless plastic chairs that were strapped onto the sides. Chairs were padded with foam and two layers of plastic bags covered each foot inside clothing to keep dressings dry. Paddles were duct-taped to jacket arms to help the patients experience paddling. The other rafters sat on the raft sides.

During the camp, volunteers were assigned to dressings on behalf of the campers' regular caregivers. This took up to 3 hours each day, giving the medical students an appreciation of the repetitive and difficult daily routine involved in EB patient care. Family caregivers provide excellent care to the patients, but their wellbeing is often affected and chronic tiredness is common. Informal caregivers to disabled people frequently report the need for short breaks, domestic help and respite care. ${ }^{3}$ The 2010 EB adventure camp played an important role as respite care, helping informal caregivers to improve their quality of life while providing opportunities for the patients to experience active outdoor activities. ${ }^{4}$

All the campers developed close relationships among themselves and with volunteers. Communication among the patients outside the medical context allowed them to feel more socially included and to learn ways of interacting with others in different social contexts. The camp allowed the young patients with EB to develop independence and provided assurance to caregivers that their patients could enjoy the camp safely under the supervision of others.

\section{among the}

patients outside

the medical

context allowed

them to feel

more socially included

Acknowledgements: We thank DEBRA NZ and DEBRA Australia for organising this adventure trip for Australian and New Zealand patients with RDEB and their volunteers. We also appreciate the wonderful contribution from all of the volunteers who participated.

\section{Competing interests: No relevant disclosures.}

1 Horn HM, Tidman MJ. The clinical spectrum of dystrophic epidermolysis bullosa. Br J Dermatol 2002; 146: 267-274.

2 Nading MA, Lahmar JJ, Frew JW, et al. A ski and adventure camp for young patients with severe forms of epidermolysis bullosa. J Am Acad Dermatol 2009; 61: 508-511.

3 Kersten P, McLellan L, George S, et al. Needs of carers of severely disabled people: are they identified and met adequately? Health Soc Care Community 2001; 9: 235-243.

4 Wolkowski A, Carr S, Clarke CL. What does respite care mean for palliative care service users and carers? Messages from a conceptual mapping. Int J Palliat Nurs 2010; 16: 388-392. 